WellBeing International

WBI Studies Repository

4-2012

\title{
Social Effects on Vocal Ontogeny in an Ungulate, the Goat, Capra hircus
}

Elodie F. Briefer

Queen Mary University of London

Alan G. McElligott

Queen Mary University of London

Follow this and additional works at: https://www.wellbeingintlstudiesrepository.org/acwp_asie

Part of the Animal Studies Commons, Comparative Psychology Commons, and the Other Animal Sciences Commons

\section{Recommended Citation}

Briefer, E. F., \& McElligott, A. G. (2012). Social effects on vocal ontogeny in an ungulate, the goat, Capra hircus. Animal Behaviour, 83(4), 991-1000.

This material is brought to you for free and open access by WellBeing International. It has been accepted for inclusion by an authorized administrator of the WBI Studies Repository. For more information, please contact wbisr-info@wellbeingintl.org.

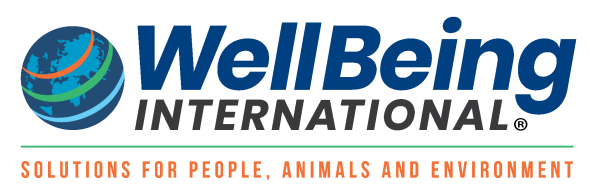




\title{
Social Effects on Vocal Ontogeny in an Ungulate, the Goat, Capra hircus
}

\author{
Elodie F. Briefer \& Alan G. McElligott \\ Queen Mary University of London
}

\section{KEYWORDS}

call convergence, Capra hircus, goat, mammal, vocal communication, vocal learning, vocal plasticity

\begin{abstract}
ABTRACT
Vocal plasticity is the ability of an individual to modify its vocalizations according to its environment. Humans benefit from an extreme form of vocal plasticity, allowing us to produce a wide range of sounds. This capacity to modify sounds has been shown in three bird orders and in a few nonhuman mammal species, all characterized by complex vocal communication systems. In other mammals, there is no evidence for a social impact on vocal development. We investigated whether contact calls were affected by social environment and kinship during early ontogeny in goats, a highly vocal and social species. To test the influence of social environment on kid vocalizations, we compared half siblings raised in the same or different groups. The effect of kinship on calls was assessed by comparing full siblings with half siblings. Calls of half siblings were more similar when they had been raised in the same social group than in different groups, and converged with time. Full siblings had more similar calls than half siblings. The group-specific indicators in kid vocalizations show that goat call ontogeny is affected by their social environment. This suggests that vocal plasticity could be more widespread in mammals than previously believed, showing a possible early pathway in the evolution of vocal learning leading to human language.
\end{abstract}

Vocalizations in most animal taxa are genetically determined and develop without any effect of the environment (Simmons et al. 2003). Apart from humans, one well-known exception to this rule concerns birds, in which three orders (hummingbirds, parrots and songbirds) learn their vocalizations. In particular, songbirds have highly developed capacities for vocal plasticity, allowing them to imitate tutors and sometimes to modify their vocalizations throughout their lives (Beecher \& Brenowitz 2005), leading to very elaborate vocal repertoires in some species (e.g. Briefer et al. 2010). However, in nonhuman mammals, vocalizations were traditionally believed to be genetically determined, with only limited anatomical flexibility and, therefore, with constraints on the capacity for vocal learning (Seyfarth \& Cheney 2010). There is now growing evidence that some species (pinnipeds: Schusterman 2008; bats: Knörnschild et al. 2010; cetaceans: Janik 2000; Noad et al. 2000; elephants, Loxodonta africana: Poole et al. 2005) are capable of vocal production learning (Janik \& Slater 1997). In those species, individuals can modify their vocalizations through social learning in order to develop group identity cues (Tyack 2008) or, by contrast, to increase distinctiveness for individual recognition (Janik et al. 2006). Unlike most mammals, humans have advanced motor control over vocalizations, important articulatory possibilities and unique vocal-learning abilities that are the basis of the evolution of speech (Fitch 2000a). The study of vocal learning in a broader range of mammals has important implications for our understanding of the evolution of vocal communication leading to human language, and of the role that ecological factors play in shaping vocal communication systems. 
Studies investigating the effects of social factors on vocalizations in mammals believed to lack the ability for vocal learning are rare for two main reasons. First, social effects are unexpected in these species because their existence implies some kind of vocal flexibility to acquire production features from social partners (Lameira et al. 2010). Second, it is difficult to show a social effect by ruling out alternative explanations (e.g. genetic and environmental factors, body size and internal state differences, Janik \& Slater 2000; Crockford et al. 2004). In wild animals, group or population differences often result from genetic variations, founder effects or adaptations to environmental or social factors (e.g. population density, preference for certain calls; Janik \& Slater 2000), rather than social learning (Lieblich et al. 1980; Mitani et al. 1999). Evidence for a social effect during ontogeny also needs careful interpretation, to rule out changes caused by maturational processes. Unlike social effects on vocal usage, which have been well studied (e.g. alarm calls, Hollén \& Radford 2009), social effects on the development of acoustic features of vocalizations ('vocal production') have been investigated only in mammals with a large variety of call types (Jones \& Ransome 1993; Knörnschild et al. 2010). Flexibility in young mammals with limited vocal repertoires could represent an early step in the evolution of vocal learning.

Table 1: Group composition

\begin{tabular}{|l|l|l|l|l|l|l|l|}
\hline Group & Mothers & Kids & Male Kids & $\begin{array}{l}\text { Female } \\
\text { Kids }\end{array}$ & $\begin{array}{l}\text { Sets of } \\
\text { Triplets }\end{array}$ & $\begin{array}{l}\text { Pairs of } \\
\text { Twins }\end{array}$ & Singletons \\
\hline 1 & 3 & 6 & 6 & 0 & 1 & 1 & 1 \\
\hline 2 & 3 & 5 & 5 & 0 & 0 & 2 & 1 \\
\hline 3 & 4 & 7 & 4 & 3 & 0 & 3 & 1 \\
\hline 4 & 3 & 5 & 3 & 2 & 0 & 2 & 1 \\
\hline
\end{tabular}

Number of mothers, kids, male and female kids, sets of triplets, pairs of twins and singleton kids in groups 1-4.

We investigated social impacts on acoustic communication in goats, a highly vocal and social species (Saunders et al. 2005; Briefer \& McElligott 2011a, b), with sophisticated cognitive skills (Kaminski et al. 2005; Langbein et al. 2008). We recorded and analysed contact calls of goat kids to determine whether and when social group and kinship identity cues occur during development. Contact calls are nonemotional social calls that animals use to maintain contact with conspecifics in low-stress situations, when they are close to each other (Muller et al. 2009).We used captive animals in this study. This allowed us to control for genetic variation between groups. The effect of the social group on vocalizations was assessed by comparing calls of half siblings raised in the same or different groups. The effect of kinship on vocalizations was assessed by comparing calls of full and half siblings. We predicted more similarities between calls of full siblings than between calls of half siblings, that is, kinship identity cues. Considering the absence of evidence for vocal learning in mammals such as goats, we did not expect to find differences in the acoustic structure of contact calls produced by half siblings raised in different social groups, that is, no noninherited group identity cues. By contrast, a similarity of call structure between goat kids raised together would indicate that vocalizations of young mammals could be more flexible than previously believed.

Contact calls of goat kids were recorded at 1 week and 5 weeks postpartum. These two periods correspond to different ecological and social conditions. Goats adopt a hider strategy for predator avoidance and therefore, during the first weeks of life, goat kids stay most of the time hidden in vegetation alone or with their sibling(s), to avoid detection by predators (McDougall 1975; Caro 2005). At 5 weeks old, however, goat kids would normally have integrated into social groups. We hypothesized that if kid 
contact calls contain group identity cues (i.e. show similarities between calls of same-age kids of a given social group), these cues should be more pronounced at 5 weeks old, when goat kids are fully integrated into the social group with other offspring of the same age, than at 1 week old, when they stay mainly alone or with their sibling(s).

\section{METHODS}

\section{Animals and Housing}

The study was carried out at White Post Farm, Nottinghamshire, U.K., on four groups of pygmy goat kids born in July and December 2009, and March and July 2010, respectively. The composition of the groups is detailed in Table 1 (mean group size $=5.75 \pm 0.48$ kids, $N=23$ kids, five females and 18 males). All kids had the same father and were thus all full or half siblings. Half siblings from the same social group were therefore not more related than half siblings from a different group. This allowed us to investigate variations between groups of similarly related kids (i.e. group effect, while controlling for potential kinship effects).

Each group (detailed in Table 1) was kept indoors in a communal pen of $4.4 \times 4.5 \mathrm{~m}$. When a female was about to give birth, she was isolated in a $2.5 \mathrm{~m}^{2}$ pen within the communal pen and kept there with her kid(s) for 2 days to allow adequate development of the mother-offspring bond and prevent interference from other goats. Mothers and kids were then released in the communal pen with the other goats and kids. Male kids were castrated following the usual procedure in the U.K., by using a constrictive rubber ring applied to the neck of the scrotum 3-4 days after birth. This was carried out as part of routine management of the animals by the owners. Because testosterone levels in male goats are very low before sexual maturity (i.e. 22 weeks on average, Chakraborty et al. 1989; Ahmad \& Noakes 1996), potential differences between castrated and intact males are likely to have had little impact on the vocalizations of goats used in our study (see also Briefer \& McElligott 2011b).

\section{Recordings and Selection of Calls}

We recorded goat kid contact calls at distances of 1--5 $\mathrm{m}$ from the vocalizing animal using a Sennheiser MKH70 directional microphone, connected to a Marantz PMD660 solid-state recorder between 1000 and 1700 hours. Kids were recorded at approximately 1 week postpartum (at 5 days old for each kid) and at approximately 5 weeks postpartum (between 34 and 39 days old for each kid). This was done by separating them for no more than $5 \mathrm{~min}$, two or three times per day in visual and hearing range (1--10 $\mathrm{m}$ ) of their mothers. The initial distance to the mother was set at $1 \mathrm{~m}$ on average and increased if necessary, until we obtained contact calls (i.e. low-affect vocalizations) and no distress calls (i.e. high-pitched vocalizations associated with high stress levels during social isolation, Lenhardt 1977; Briefer \& McElligott 2011b). Kids were isolated alone, unless they appeared stressed during isolation even at $1 \mathrm{~m}$. In these cases, they were isolated with their sibling(s). Vocalizations were then imported into a computer at a sampling rate of $44.1 \mathrm{kHz}$ and saved in WAV format at 16-bit amplitude resolution. We used Praat v.5.0.47 DSP Package (Boersma \& Weenink 2009) and Seewave (Sueur et al. 2008) for subsequent analyses. Calls were visualized on spectrograms in Praat (FFT method, window length $0.01 \mathrm{~s}$, time steps $=1000$, frequency steps $=250$, Gaussian window shape, dynamic range $=50 \mathrm{~dB}$ ).

\section{Acoustic Analysis}

We selected eight good-quality calls (low levels of background noise as visualized on a spectrogram) per kid at both $5.0 \pm 0.0$ (approximately 1 week old) and $36.0 \pm 0.3$ (approximately 5 weeks old) days old (total: 23 kids; 184 calls for each age) for subsequent analyses. Goat open-mouth contact calls are short, 
with a clear harmonic structure and strong frequency and amplitude modulations (Appendix Fig. A1). According to the source-filter theory of voice production (Fant 1960), mammal vocalizations are generated by vibrations of the vocal folds (source, determining the fundamental ' $F 0$ '), and are subsequently filtered by the supralaryngeal vocal tract (filter, producing amplified frequencies called 'formants', Titze 1994). Using a custom-built program in Praat, we extracted source-related acoustic features (FO contour) and filter-related acoustic features (formants and energy quartiles; 23 parameters in total), which can potentially be manipulated by muscles of the vocal folds and vocal tract, respectively, in mammals and could thus be influenced by the social environment (Taylor \& Reby 2010). The program batch-processed the editing, the setting of parameters, the analyses and the exporting of output data (Reby \& McComb 2003; Charlton et al. 2009). The vocal parameters that we measured are listed in Table 2 and the analyses are detailed in Briefer \& McElligott (2011a, b).

Table 2: Abbreviations and brief descriptions for the vocal parameters measured

\begin{tabular}{|l|l|}
\hline Abbreviation & Parameter \\
\hline Dur $(\mathrm{s})$ & Duration of the call \\
\hline F0Mean $(\mathrm{Hz})$ & Mean F0 frequency value across the call \\
\hline F0Start $(\mathrm{Hz})$ & Frequency value of F0 at the start of the call \\
\hline F0End $(\mathrm{Hz})$ & Frequency value of F0 at the end of the call \\
\hline F0Max $(\mathrm{Hz})$ & Maximum F0 frequency value across the call \\
\hline F0Min $(\mathrm{Hz})$ & Minimum F0 frequency value across the call \\
\hline F0AbsSlope $(\mathrm{Hz} / \mathrm{s})$ & F0 mean absolute slope \\
\hline Q25\% $(\mathrm{Hz})$ & $\begin{array}{l}\text { Frequency value at the upper limit of the } \\
\text { first quartiles of energy }\end{array}$ \\
\hline Q50\% $(\mathrm{Hz})$ & $\begin{array}{l}\text { Frequency value at the upper limit of the } \\
\text { second quartiles of energy }\end{array}$ \\
\hline Q75\% $(\mathrm{Hz})$ & $\begin{array}{l}\text { Frequency value at the upper limit of the } \\
\text { third quartiles of energy }\end{array}$ \\
\hline F1Min $(\mathrm{Hz})$ & Minimum frequency value of the first formant \\
\hline F2Min $(\mathrm{Hz})$ & Minimum frequency value of the second formant \\
\hline F3Min $(\mathrm{Hz})$ & Minimum frequency value of the third formant \\
\hline F4Min $(\mathrm{Hz})$ & Minimum frequency value of the fourth formant \\
\hline F1Max $(\mathrm{Hz})$ & Maximum frequency value of the first formant \\
\hline F2Max $(\mathrm{Hz})$ & Maximum frequency value of the second formant \\
\hline F3Max $(\mathrm{Hz})$ & Maximum frequency value of the third formant \\
\hline F4Max $(\mathrm{Hz})$ & Maximum frequency value of the fourth formant \\
\hline F1Mean $(\mathrm{Hz})$ & Mean frequency value of the first formant \\
\hline F2Mean $(\mathrm{Hz})$ & Mean frequency value of the second formant \\
\hline F3Mean $(\mathrm{Hz})$ & Mean frequency value of the third formant \\
\hline F4Mean $(\mathrm{Hz})$ & Mean frequency value of the fourth formant \\
\hline DfMin $(\mathrm{Hz})$ & Minimum spacing of the formants \\
\hline
\end{tabular}




\section{Statistical Analysis}

To assess the effect of kinship and group membership on the acoustic parameters of kid calls, we calculated Euclidean distances between individuals according to the characteristics of their calls and we performed permutation and partial Mantel tests on these distances (Mantel 1967; Sokal \& Rohlf 1995; Charlton et al. 2009). Calls of kids at 1 week and 5 weeks old were treated separately in the various analyses. We carried out statistical analyses using R v.2.9.0 (R Development Core Team 2009). All means are given with SEs.

\section{Overall similarity between individuals}

1. Overall call similarity. To assess the effect of kinship and group membership on the overall acoustic structure of calls, we first used a principal components analysis (PCA) to eliminate redundancy caused by the high intercorrelation of the acoustic variables in our data. We checked whether our data deviated significantly from a normal distribution (Kolmogorove-Smirnov test) and log-transformed them when necessary. Then, data were used as input variables in the PCA. We retained the principal components (PCs) of the PCA with eigenvalues greater than 1 (Kaiser's criterion). The scores of these PCs were then averaged for each kid to obtain individual centroids, and we calculated Euclidean distances between these centroids for each pair of kids (hereafter 'overall distances').

2. Vocal parameter similarity. To assess the effect of kinship and group membership on each vocal parameter, we checked whether our data deviated significantly from a normal distribution (Kolmogorove-Smirnov test) and log-transformed them when necessary. We then generated matrices of Euclidean distances between individual mean values ( $N=23$ kids), for each vocal parameter one by one.

All tests were then carried out on Euclidean distances between individuals (overall distances calculated using PC scores or distances calculated for each vocal parameter).

\section{Changes in vocal similarity}

Because conventional parametric and nonparametric tests are not suitable for analyses in which each individual is included several times in the different pairwise comparisons (Mundry 1999), we used twotailed dependent or independent exact permutation tests to compare overall distances between the following categories: same group half siblings at 1 week and 5 weeks old; different group half siblings at 1 week and 5 weeks old; full siblings at 1 week and 5 weeks old; half siblings at 1 week and 5 weeks old. We used Bonferroni adjustments to correct for multiple testing, and results of the permutation tests retained significance when $\mathrm{P}<0.017$ (i.e. $0.05 / 3$, as each category was included in three comparisons).

\section{Group and kinship effects}

To investigate group and kinship effects on vocal parameters and overall structure, we used partial Mantel tests, which test for the correlation between two distance matrices while controlling for a third one and deal with the problem of dependence between values by using a randomization test (Mantel 1967; Sokal \& Rohlf 1995), on overall distances between individuals and distances calculated for each vocal parameter. We first calculated the correlation between vocal similarity (Euclidean distances) and group membership while controlling for kinship and vice versa. Additionally, we carried out more partial Mantel tests, first to calculate correlations between vocal similarity and group membership/kinship while controlling for sex, and second to calculate correlations between vocal similarity and group membership/kinship while controlling for the day when kid calls had been recorded. Pairwise kinship of individuals was quantified using the coefficient of relatedness $r$, which is the degree to which two individuals share identical alleles: $r=0.50$ for full siblings and $r=0.25$ for half siblings. Group membership, sex and day of recording similarities were indicated as 1 when individuals were from the same group, sex or recorded on the same day and 0 when individuals were from a different group, sex or 
recorded on a different day. We used Bonferroni adjustments to correct for multiple testing, and results of the Mantel tests retained significance when $\mathrm{P}<0.01$ (i.e. $0.05 / 5$, as five Mantel tests were carried out on each set of data in total).

\section{Ethical Note}

The goats were owned by White Post Farm, Nottinghamshire, U.K. (http://whitepostfarmcentre.co.uk/). This farm breeds three to five female goats at three different times of the year, and gave us free access to the kids. Routine care of the animals was given by farm employees. All goats were kept indoors in a communal pen of $4.4 \times 4.5 \mathrm{~m}$ with straw bedding. The pens were provided with an automatic water dispenser and a hayrack. Goats had ad libitum access to hay and water and were also fed with a commercial concentrate. During our recordings,mothers and kids could always see each other and were separated for periods of less than $5 \mathrm{~min}$ at $1--10 \mathrm{~m}$.

\section{RESULTS}

\section{Overall Similarity between Individuals}

For both 1-week-old and 5-week-old kids, the first component of the PCA was highly correlated $(r>0.50)$ with formant values and the second with F0 values (Appendix Tables A1, A2). The PCAs generated four PCs for 1-week-old kid calls and six PCs for 5-weekold kid calls that exceeded Kaiser's criterion (eigenvalues $>1 ; 81.03 \pm 0.89 \%$ of the variation in the original data sets) and that were therefore used to calculated overall Euclidean distances between individuals.

\section{Changes in Vocal Similarity}

The permutation tests indicated that calls of half siblings from the same group were more similar than calls of half siblings from different groups, and full-sibling calls were more similar than half sibling calls, at 5 weeks old, but not at 1 week old. The similarity between calls increased between 1 week and 5 weeks old for all categories of individuals (Figs 1, 2).

Distances (i.e. dissimilarities between calls) between same group half siblings (SG) were not significantly different from distances between different group half siblings (DG) at 1 week old (independent exact permutation tests: $N=238$ pairwise comparisons, $P=0.15$; Fig. 2a). However, at 5 weeks old, distances between SG were shorter than those between DG, indicating that SG had more similar calls than DG (independent exact permutation tests: $\mathrm{N}=238$ pairwise comparisons, $\mathrm{P}<0.0001$; Fig. 2a). Distances decreased between 1 week and 5 weeks old for both SG (dependent exact permutation tests: $N=45$ pairwise comparisons, $P<0.0001$ ) and DG (dependent exact permutation tests: $N=193$ pairwise comparisons, P < 0.0001; Fig. 2a). At 1 week old, distances between SG were not significantly different from those between full siblings ( $F S$, independent exact permutation tests: $N=60$ pairwise comparisons, $P=0.99$; Fig. 2a, b). At 5 weeks old, however, distances between SG were longer than those between FS (independent exact permutation tests: $N=60$ pairwise comparisons, $P=0.007$; Fig. $2 a$, b). This indicates that SG calls were as similar as FS calls at 1 week old, but less similar than FS calls at 5 weeks old. All these results remained significant after Bonferroni correction $(P<0.017)$.

Distances (i.e. dissimilarities between calls) between FS were not significantly different from distances between half siblings (HS) at 1 week old (independent exact permutation tests: $N=253$ pairwise comparisons, $\mathrm{P}=0.50$; Fig. 2b). However, at 5 weeks old, distances between FS were shorter than those between HS, indicating that FS had more similar calls than HS (independent exact permutation tests: $\mathrm{N}=$ 253 pairwise comparisons, $\mathrm{P}<0.0001$; Fig. 2b). Both distances between FS (dependent exact permutation tests: $\mathrm{N}=15$ comparisons, $\mathrm{P}=0.0001$ ) and distances between HS (dependent exact 
permutation tests: $\mathrm{N}=238$ comparisons, $\mathrm{P}<0.0001$ ) decreased between 1 week and 5 weeks old (Fig. $2 b)$. All these results remained significant after Bonferroni correction $(P<0.017)$.

Figure 1. Similarities between calls of individuals at (a) 1 week and (b) 5 weeks old. Plot of the first principal component (PC1) against the second principal component (PC2) extracted from the principal components analysis (PCA) including all vocal parameters. Each dot corresponds to the PCA centroid of an individual. Kids of the same group ( $N=23$ kids, four groups, delimited with lines) are indicated with the same shape and same colour and kids born from the same mother (full siblings) are indicated with the same number ( $\mathrm{N}=12$ mothers). The closer two individuals are on the plot, the more similar their call structure is.

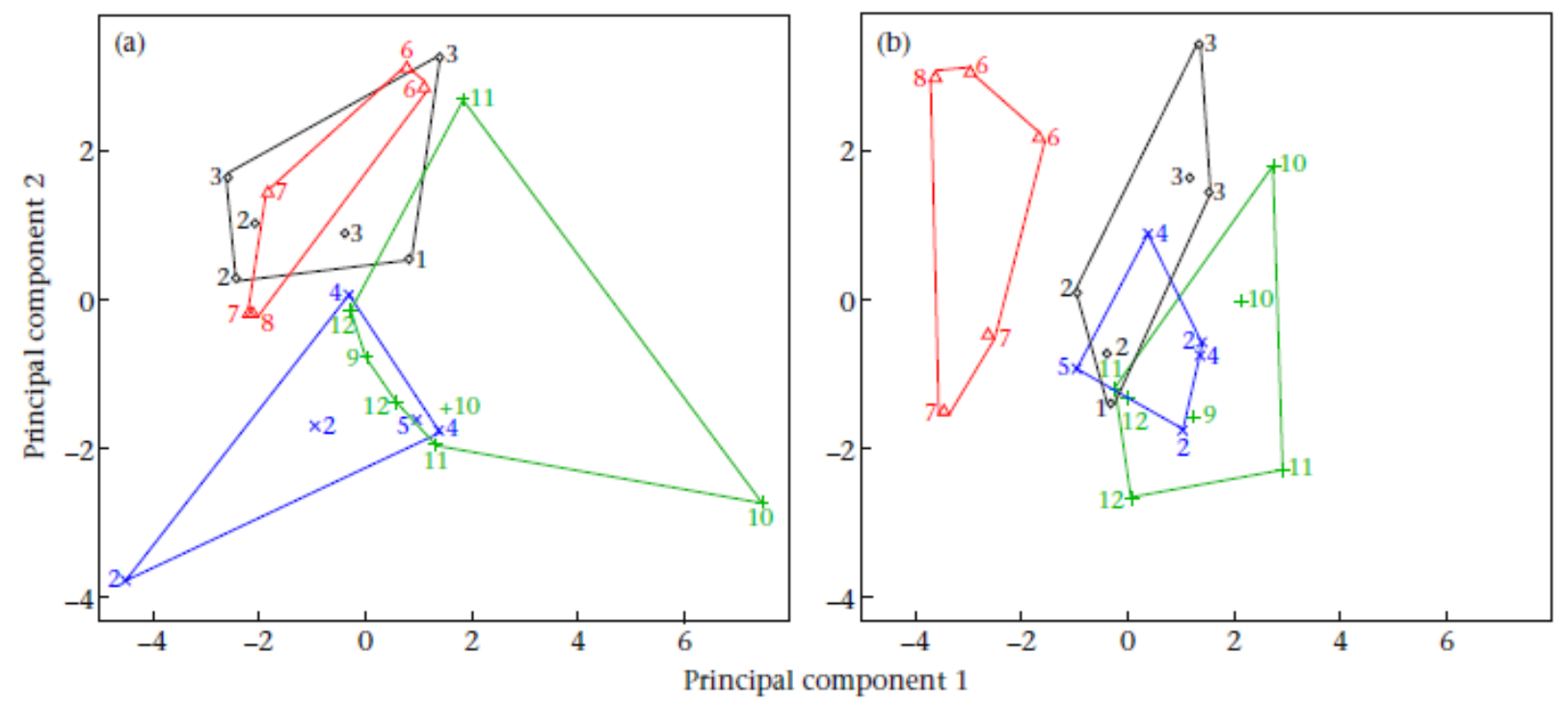

Group and Kinship Effects

The partial Mantel tests showed that kids from the same group had more similar overall call structures than kids from different groups, at both 1 week (before Bonferroni correction) and 5 weeks old. Their calls had more similar fundamental frequency contours and energy spectrums at 1 week old, and more similar energy spectrums and formant contours at 5 weeks old. Full siblings had more similar overall call structures than half siblings at 5 weeks old, but not at 1 week. At 5 weeks old, their calls had more similar fundamental frequency contours (before Bonferroni correction) and formant contours (Table 3; Appendix Tables A3, A4).

Group membership was negatively correlated with overall Euclidean distances (i.e. dissimilarities) between calls of individuals, indicating that kids from the same group had more similar calls, at both 1 week and 5 weeks old. Kinship was negatively correlated with overall Euclidean distances between individuals, indicating that similarity between calls increased with kinship at 5 weeks old, but not at 1 week. The correlations at 5 weeks old were also significant when controlling for sex and day of recording, and after Bonferroni correction ( $\mathrm{P}<0.01)$, for both group membership and kinship (Table 3).

At 1 week old, group membership was correlated with all F0-related parameters and some spectrumrelated parameters (energy quartiles: Q25\% and Q50\%; Table 3). All these correlations were also significant when controlling for sex and day of recording, except F0Max ( $r$-- -0.07, P -- 0.081 when controlling for sex; $r---0.09, P$-- 0.055 when controlling for day of recording), and F0Mean ( $r$-- $-0.11, P$-0.050 when controlling for sex). The correlations with F0Min, F0AbsSlope, Q25\% and Q50\%, including 
the controls (sex and day of recording), remained significant after Bonferroni correction $(P<0.01)$. At 5 weeks old, group membership was correlated with FOMin, all spectrum-related parameters (energy quartiles) and some formant-related parameters (second and third formants; Table 3). All these correlations were also significant when controlling for sex and day of recording, except F0Min ( $r^{1 / 4} \_0.09, P$ $1 / 40.062$ when controlling for day of recording) and F3Mean ( $r---0.04, P--0.22$ when controlling for day of recording). The correlations with Q50\%, Q75\% and F2Min, including the controls (sex and day of recording), remained significant after Bonferroni correction $(P<0.01)$.

Figure 2. Group and kinship similarities. (a) Euclidean distances between PCA centroids of half siblings from the same group (SG, black, $N=45$ pairwise comparisons) versus half siblings from different groups (DG, grey, $N=193$ pairwise comparisons) at 1 week and 5 weeks old (mean \pm SE pairwise distances). (b) Euclidean distances between PCA centroids of full siblings ( $F S$, black, $N=15$ pairwise comparisons) versus half siblings at 1 week and 5 weeks old (HS, grey, $\mathrm{N}=238$ pairwise comparisons). Two-tailed exact permutation tests: ${ }^{* \star *} \mathrm{P}<0.001$. Shorter distances between individuals indicate more similar call structure.
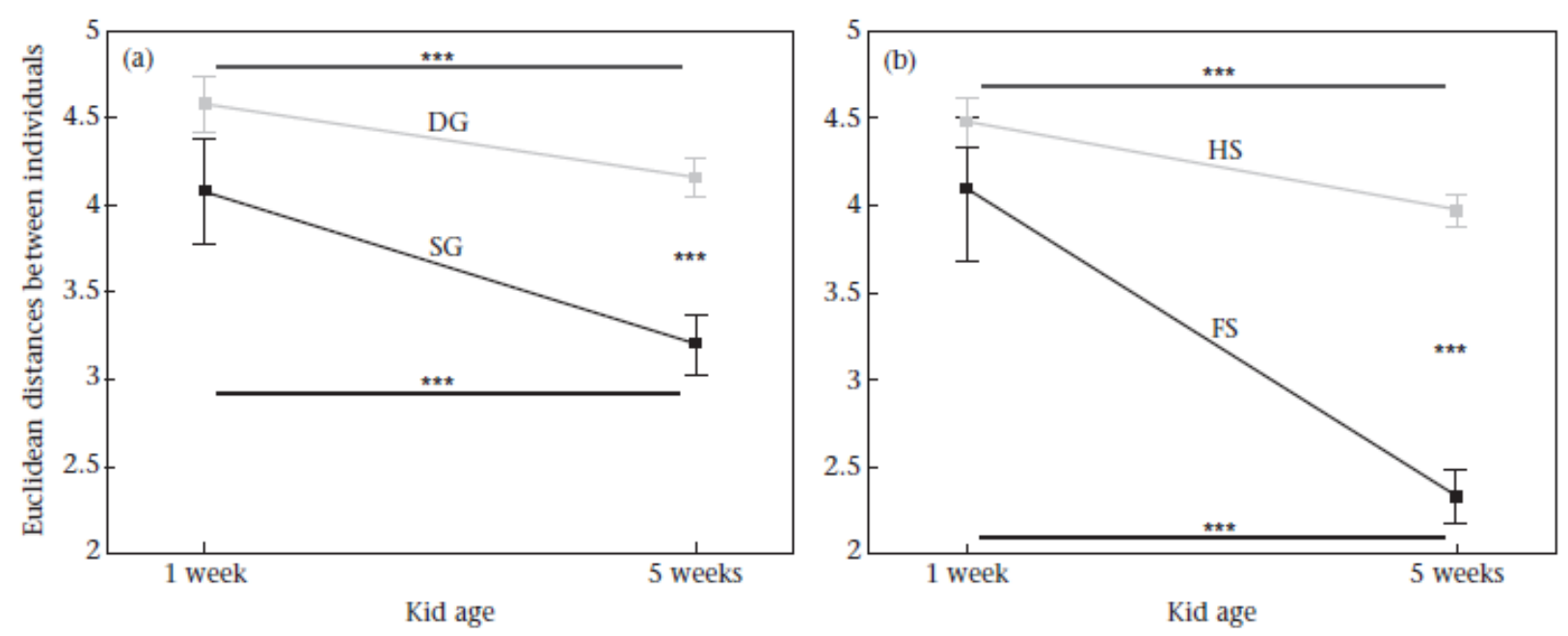

At 1 week old, kinship was only correlated with call duration (Table 3). However, this correlation was not significant when controlling for the day of recording $(r=-0.05, P=0.23)$. At 5 weeks old, kinship influenced some F0-related parameters (F0Mean, F0Start and FOMax), Q75\% and some formant-related parameters (first and fourth formants and DfMin; Table 3). These correlations were also significant when controlling for sex and day of recording, except Q75\% ( $r=0.05, P=0.17$ when controlling for sex), F1Min ( $r--0.08, P=0.14$ when controlling for day of recording), F4Min $(r---0.10, P=0.082$ when controlling for day of recording) and DfMin ( $r=-0.10, P=0.097$ when controlling for day of recording). The correlations with F1Max and F4Max, including the controls (sex and day of recording), remained significant after Bonferroni correction $(P<0.01)$. 
Table 3 Relationship between call structure and group membership and kinship

\begin{tabular}{|c|c|c|c|c|c|c|c|c|}
\hline \multirow[t]{3}{*}{ Parameter } & \multicolumn{4}{|c|}{ One-week-old kids } & \multicolumn{4}{|c|}{ Five-week-old kids } \\
\hline & \multicolumn{2}{|l|}{ Group } & \multicolumn{2}{|l|}{ Kinship } & \multicolumn{2}{|l|}{ Group } & \multicolumn{2}{|l|}{ Kinship } \\
\hline & $r_{s}$ & $P$ & $r_{s}$ & $P$ & $r_{s}$ & $P$ & $r_{s}$ & $P$ \\
\hline Overall & -0.12 & 0.020 & 0.03 & 0.34 & -0.25 & $0.001^{*}$ & -0.21 & $0.003^{\prime}$ \\
\hline Dur (s) & -0.03 & 0.29 & -0.12 & 0.035 & 0.44 & 0.30 & 0.01 & 0.46 \\
\hline FOMean (Hz) & -0.13 & 0.023 & 0.09 & 0.06 & 0.01 & 0.47 & -0.14 & 0.020 \\
\hline F0Start (Hz) & -0.16 & 0.012 & 0.06 & 0.18 & -0.08 & 0.09 & -0.13 & 0.038 \\
\hline FOEnd $(\mathrm{Hz})$ & -0.16 & 0.007 & 0.10 & 0.07 & -0.09 & 0.058 & -0.04 & 0.24 \\
\hline FOMax $(\mathrm{Hz})$ & -0.10 & 0.036 & 0.09 & 0.075 & 0.02 & 0.39 & -0.11 & 0.037 \\
\hline FOMin $(\mathrm{Hz})$ & -0.20 & $0.007^{*}$ & 0.06 & 0.19 & -0.12 & 0.027 & -0.08 & 0.10 \\
\hline F0AbsSlope (Hz/s) & -0.24 & $0.002^{*}$ & -0.08 & 0.14 & 0.01 & 0.49 & -0.06 & 0.19 \\
\hline Q25\% (Hz) & -0.22 & $0.003^{*}$ & 0.01 & 0.42 & -0.15 & 0.016 & -0.09 & 0.07 \\
\hline Q50\% (Hz) & -0.24 & $0.003^{*}$ & 0.00 & 0.48 & -0.29 & $0.001^{*}$ & 0.04 & 0.28 \\
\hline Q75\% (Hz) & -0.10 & 0.076 & -0.02 & 0.38 & -0.26 & $0.002^{*}$ & 0.14 & 0.006 \\
\hline F1Min (Hz) & -0.06 & 0.15 & 0.02 & 0.46 & -0.02 & 0.29 & -0.12 & 0.036 \\
\hline F2Min $(\mathrm{Hz})$ & 0.03 & 0.27 & -0.08 & 0.10 & -0.22 & $0.002^{*}$ & -0.09 & 0.08 \\
\hline F3Min $(\mathrm{Hz})$ & 0.02 & 0.42 & 0.00 & 0.47 & -0.19 & 0.004 & -0.05 & 0.20 \\
\hline F4Min $(\mathrm{Hz})$ & -0.01 & 0.40 & 0.04 & 0.30 & 0.01 & 0.41 & -0.15 & 0.011 \\
\hline F1Max (Hz) & 0.01 & 0.48 & 0.03 & 0.31 & -0.01 & 0.39 & -0.17 & $0.005^{\prime}$ \\
\hline F2Max (Hz) & 0.04 & 0.25 & 0.01 & 0.46 & -0.09 & 0.066 & -0.04 & 0.30 \\
\hline F3Max (Hz) & 0.02 & 0.39 & -0.01 & 0.41 & -0.09 & 0.076 & -0.04 & 0.27 \\
\hline F4Max (Hz) & -0.01 & 0.41 & -0.01 & 0.47 & 0.03 & 0.30 & -0.23 & $0.001^{\prime}$ \\
\hline F1Mean $(\mathrm{Hz})$ & -0.01 & 0.33 & 0.01 & 0.45 & -0.06 & 0.15 & -0.08 & 0.10 \\
\hline F2Mean $(\mathrm{Hz})$ & 0.07 & 0.10 & -0.03 & 0.29 & -0.14 & 0.013 & -0.03 & 0.31 \\
\hline F3Mean $(\mathrm{Hz})$ & 0.02 & 0.38 & 0.01 & 0.49 & -0.12 & 0.031 & -0.05 & 0.21 \\
\hline F4Mean $(\mathrm{Hz})$ & -0.06 & 0.11 & 0.03 & 0.34 & 0.02 & 0.42 & -0.19 & 0.003 \\
\hline DfMin $(\mathrm{Hz})$ & -0.02 & 0.39 & 0.06 & 0.18 & 0.02 & 0.41 & -0.12 & 0.036 \\
\hline
\end{tabular}

Spearman correlation coefficients and $\mathrm{P}$ values for partial Mantel tests investigating the correlation between-group membership controlling for kinship (Group), or vice versa (Kinship), and Euclidean distances between goat kid calls at 1 week and 5 weeks old. Negative correlations indicate that kids that were from the same group (Group) or that were closely related (Kinship) had more similar calls (Overall) or vocal parameters than kids that were from different groups or that were less closely related, respectively. Bold type indicates results that were also significant $(P<0.05)$ when controlling for sex and day of recording, and an asterisk denotes when all correlations were still significant after Bonferroni adjustments $(P<0.01)$. See Table 2 for abbreviations of the vocal parameters.

\section{DISCUSSION}

We investigated social impacts on vocal ontogeny, through the emergence of non-inherited group membership and kinship indicators, in the vocalizations of maturing goat kids. Contrary to the prevailing views in the literature, we found that calls of kids raised in the same social groups were more similar than calls of kids from different groups, showing that kids can modify their vocalizations in relation to their social environment. This social group effect was present at both 1 week (before Bonferroni correction) and 5 weeks old. As we predicted, the group effect was stronger at 5 weeks old, when kids in the wild would have joined their larger social groups of other kids and adults (Lickliter 1987). We also found that at 
1 week, full-sibling calls were not more similar than half-sibling calls. However, as kids grew older, fullsibling calls became more similar than half-sibling calls (i.e. at 5 weeks). Whereas full siblings probably have more similar calls because some of the physical features of their vocal apparatus are similar, the group effect we found probably results from the social environment affecting vocal production during ontogeny. Vocal learning is already well known in several orders of birds, but is rare in mammals (Janik \& Slater 1997; Beecher \& Brenowitz 2005). To our knowledge, vocal learning has not been shown in any ungulate until now. Our results are highly novel because they provide evidence for flexibility of calls during development in an ungulate with a limited vocal repertoire that is believed not to be capable of vocal learning, the goat. Therefore the role of social impacts on vocal communication during development in non-vocal learners has probably been greatly underestimated (Janik \& Slater 2000).

To date, the development of calls in mammals such as goats was believed to be unaffected by environmental or social experience (Janik \& Slater 1997). Surprisingly, we found that calls of half siblings were more similar at 1 week old when they had been raised together than when raised in different groups, and became even more similar at 5 weeks old. Convergence of acoustic features of calls among adult individuals housed together or forming natural groups has been shown in some mammals with complex vocal communication systems, including bats and elephants (Tyack 2008). This phenomenon is generally seen, along with 'vocal imitation' (i.e. the acquisition of novel vocalizations from a tutor), as evidence for vocal production learning (i.e. vocal changes as a consequence of experience with conspecifics; Janik \& Slater 2000; Boughman \& Moss 2003; Tyack 2008). Therefore our results suggest that goat kids are capable of some vocal production learning or plasticity. However, call convergence has also been reported in a few adult nonhuman primates (Crockford et al. 2004; Snowdon 2009), in which clear evidence for vocal learning is controversial (reviewed in Egnor \& Hauser 2004). Indeed, the obvious evidence for vocal production learning is the imitation of novel sounds, whereas call convergence mainly involves changes in the structure of existing calls (e.g. Elowson \& Snowdon 1994; Sugiura 1998), similar to what we found in this study. Call convergence has been suggested to have a broader taxonomic range than vocal imitation (Tyack 2008). Our results clearly show that this phenomenon is evident in mammals such as goats, which have relatively simple vocalizations.

Call convergence usually arises in species with fission-fusion societies (e.g. goats; Shi et al. 2005), suggesting a function of group recognition for facilitating social integration between group members (Tyack 2008). Goats adopt a hider strategy for predator avoidance, with kids staying concealed in vegetation alone or with their sibling(s) during the first weeks after birth before joining social groups. In feral goats, the hiding phase can last for up to 6 weeks (McDougall 1975). In domestic goats, hiding behaviour is shorter (4-7 days), but also observed even under intensive farm conditions when provided with appropriate hiding sites (Lickliter 1984). After joining social groups, kids form cohesive crèches of similarly aged animals, and may spend even more time with non-sibling age mates than with their sibling(s) or mothers (Lickliter 1987; O'Brien 1988). Accordingly, we found that the group similarity was stronger at 5 weeks old than at 1 week, when kids normally live in social groups. This could provide an important role for call convergence of increasing social cohesiveness from a very early age between kids from the same crèche group. Call convergence could also lead to the development of group signatures that facilitate cohesion in adult groups. Adult females live with their kids in exclusive matrilineal groups (hefts, Boyd 1981; O'Brien 1988), and therefore vocal convergence leading to social cohesiveness is also likely to be important for adults. The group effect on some vocal parameters that we found at 1 week old (corresponding to the phase when kids hide), could be explained by the domestic setting of our study. In farms, because of the limited sizes of enclosures, goat kids were always in close proximity to other kids with whom they interacted (siblings or not; E. F. Briefer, personal observation). This close proximity between kids could explain why a group effect arose so early in our study. It would be extremely difficult 
to carry out a similar study with wild or feral goats, which live in mountainous areas, but this would allow us to investigate when a group effect arises in a natural setting.

Variation in vocalizations between groups can result from multiple factors other than vocal learning: genetic or environmental variations, differences in body size, age, physical condition, sex or internal states. Causes of group differences should thus be interpreted with caution (Janik \& Slater 2000). In our study, groups differed neither genetically nor spatially, ruling out genetic and environmental factors. Our analyses were carried out on kid calls recorded when they were the same age and therefore of similar body sizes. Because all kids were at the same farm, between-group differences in physical condition are also highly improbable. Sex and day of recording effects were controlled, excluding the effect of potential sex- or day-related (e.g. differences in affective states) variations between groups. Furthermore, our analyses were carried out on contact calls (i.e. low-affect vocalizations) and not distress calls (i.e. highpitched vocalizations associated with high stress levels, Lenhardt 1977; Briefer \& McElligott 2011b), ruling out potential differences in stress response between groups that could affect their vocalizations. The only noticeable difference between our groups of kids was that they were born at different times of year (two groups in July, with a 1-year interval, one group in December and one group in March). Time of year could potentially have affected the internal state of kids and thus their vocal parameters, but calls of kids in the two groups recorded in July (black and blue lines on Fig. 1) do not appear as more similar than the other groups. Differences in body size, age, physical condition, sex or internal states are thus unlikely explanations for the group differences observed.

The increase in similarity that we observed between 1 week and 5 weeks old for full siblings is likely to be the result of genetically determined maturation processes. Such processes could also explain the increase in similarity with time that we found for all categories of individuals (full and half siblings, from the same and different groups). Because all kids in our study were half siblings, kinship effects probably induced a small increase in similarity between half siblings in general, and between half siblings from different groups. Alternatively, because goat kids spend more time with their twins than with other age mates at a young age (Lickliter 1987), the similarity between full siblings could be caused by a combination of genetic and social components, with twins copying each other's vocalizations (Knörnschild et al. 2007). In contrast, it is likely that the vocalizations of unrelated kids become less similar with time (i.e. diverge), in the same way as other mammals (e.g. noctule bat, Nyctalus noctula: Knörnschild et al. 2007). This kinship signature could facilitate mother-kid vocal recognition, in addition to the individual signature, which becomes more salient as kids grow older (Briefer \& McElligott 2011a). Therefore, maturation processes during ontogeny lead to a simultaneous increase in both the individual and kinship distinctiveness of calls.

In domestic or feral goats, crèche groups are likely to be composed of both unrelated offspring and full and half siblings, where one male fathers several kids (Saunders et al. 2005). Our results show that, at 5 weeks old, kinship and social group effects were similarly important in shaping the overall structure of vocalizations ( $r$ values: group -- -0.25 ; kinship -- -0.21 ). However, they influenced different parameters of the calls. Kinship influenced the FO contour (before Bonferroni correction) and the first and fourth formants. The social group influenced the energy distribution in the spectrum (energy quartiles) and the second and third (before Bonferroni correction) formants, probably by changing the shape and length of the vocal tract (Fitch 2000b). Therefore, both kinship and social group effects on vocalizations could play an important role in shaping call convergence within a group.

To conclude, our study provides evidence for a social impact on the ontogeny of vocalizations in a mammal with a limited vocal repertoire, the goat. Therefore, even in mammals that do not seem to require auditory experience to develop normal vocalizations, the social environment may play a role in enhancing call similarities between conspecifics (Janik \& Slater 2000). Our results support the growing and 
controversial evidence that social context plays a role in shaping vocal communication systems (Snowdon 2009). Such surprising plasticity could be present in most mammals, but has gone undetected. This suggests an early step in the evolution of vocal communication, leading to the advanced and unique vocal-learning abilities found in humans, which allow us to speak.

\section{Acknowledgments}

We are grateful to E. Antill, C. Booth, E. Cant, C. Charpin, K. Cho Geun-A, C. Farrington, F. Galbraith, E. Landy, M. Padilla de la Torre and M. Wang for assistance, to B. Charlton and R. Mundry for statistical advice, and to L. Hollén, M. Knörnschild, H. Kunc, M. Manser, F. Nottebohm and S. Rossiter for helpful comments on the manuscript. We thank D. Reby for providing the custom-built program in Praat. E. Briefer is funded by a Swiss National Science Foundation fellowship. We acknowledge the financial support of the University of London Central Research Fund. We thank the staff of White Post Farm (http://whitepostfarmcentre.co.uk/) for their help and free access to the animals.

\section{References}

Ahmad, N. \& Noakes, D. E. 1996. Sexual maturity in British breeds of goat kids. British Veterinary Journal, 152, 93-103.

Beecher, M. D. \& Brenowitz, E. A. 2005. Functional aspects of song learning in songbirds. Trends in Ecology \& Evolution, 20, 143-149.

Boersma, P. \& Weenink, D. 2009. Praat: Doing Phonetics by Computer. http://www.praat.org/.

Boughman, J. \& Moss, C. 2003. Social sounds: vocal learning and development of mammal and bird calls. In: Acoustic Communication (Ed. by A. Simmons, R. Fay \& A. Popper), pp. 138-224. New York: Springer.

Boyd, I. L. 1981. Population changes and the distribution of a herd of feral goats (Capra sp.) on Rhum, Inner Hebrides, 1960e78. Journal of Zoology, 193, 287-304.

Briefer, E. \& McElligott, A. G. 2011a. Mutual mother-offspring vocal recognition in an ungulate hider species (Capra hircus). Animal Cognition, 14, 585-598.

Briefer, E. \& McElligott, A. G. 2011b. Indicators of age, body size and sex in goat kid calls revealed using the source-filter theory. Applied Animal Behaviour Science, 133, 175-185.

Briefer, E., Osiejuk, T. S., Rybak, F. \& Aubin, T. 2010. Are bird song complexity and song sharing shaped by habitat structure? An information theory and statistical approach. Journal of Theoretical Biology, 262, 151-164.

Caro, T. M. 2005. Antipredator Defenses in Birds and Mammals. Chicago: University of Chicago Press.

Chakraborty, P. K., Stuart, L. D. \& Brown, J. L. 1989. Puberty in the male Nubian Goat: serum concentrations of $\mathrm{LH}, \mathrm{FSH}$ and testosterone from birth through puberty and semen characteristics at sexual maturity. Animal Reproduction Science, 20, 91-101.

Charlton, B. D., Zhihe, Z. \& Snyder, R. J. 2009. Vocal cues to identity and relatedness in giant pandas (Ailuropoda melanoleuca). Journal of the Acoustical Society of America, 126, 2721-2732. 
Crockford, C., Herbinger, I., Vigilant, L. \& Boesch, C. 2004. Wild chimpanzees produce group-specific calls: a case for vocal learning? Ethology, 110, 221-243.

Egnor, S. E. R. \& Hauser, M. D. 2004. A paradox in the evolution of primate vocal learning. Trends in Neurosciences, 27, 649-654.

Elowson, A. M. \& Snowdon, C. T. 1994. Pygmy marmosets, Cebuella pygmaea, modify vocal structure in response to changed social environment. Animal Behaviour, 47, 1267-1277.

Fant, G. 1960. Acoustic Theory of Speech Production. The Hague: Mouton.

Fitch, W. T. 2000a. The evolution of speech: a comparative review. Trends in Cognitive Sciences, 4, 258267.

Fitch, W. T. 2000b. The phonetic potential of nonhuman vocal tracts: comparative cineradiographic observations of vocalizing animals. Phonetica, 57, 205-218.

Hollén, L. I. \& Radford, A. N. 2009. The development of alarm call behaviour in mammals and birds. Animal Behaviour, 78, 791-800.

Janik, V. M. 2000. Whistle matching in wild bottlenose dolphins (Tursiops truncatus). Science, 289, 13551357.

Janik, V. M. \& Slater, P. J. B. 1997. Vocal learning in mammals. Advances in the Study of Behavior, 26, 59-99.

Janik, V. M. \& Slater, P. J. B. 2000. The different roles of social learning in vocal communication. Animal Behaviour, 60, 1-11.

Janik, V. M., Sayigh, L. S. \& Wells, R. S. 2006. Signature whistle shape conveys identity information to bottlenose dolphins. Proceedings of the National Academy of Sciences, U.S.A., 103, 8293-8297.

Jones, G. \& Ransome, R. D. 1993. Echolocation calls of bats are influenced by maternal effects and change over a lifetime. Proceedings of the Royal Society B, 252, 125-128.

Kaminski, J., Riedel, J., Call, J. \& Tomasello, M. 2005. Domestic goats, Capra hircus, follow gaze direction and use social cues in an object choice task. Animal Behaviour, 69, 11-18.

Knörnschild, M., Von Helversen, O. \& Mayer, F. 2007. Twin siblings sound alike: isolation call variation in the noctule bat, Nyctalus noctula. Animal Behaviour, 74, 1055-1063.

Knörnschild, M., Nagy, M., Metz, M., Mayer, F. \& von Helversen, O. 2010. Complex vocal imitation during ontogeny in a bat. Biology Letters, 6, 156-159.

Lameira, A. R., Delgado, R. A. \& Wich, S. A. 2010. Review of geographic variation in terrestrial mammalian acoustic signals: human speech variation in a comparative perspective. Journal of Evolutionary Psychology, 8, 309-332.

Langbein, J., Siebert, K. \& Nuernberg, G. 2008. Concurrent recall of serially learned visual discrimination problems in dwarf goats (Capra hircus). Behavioural Processes, 79, 156-164.

Lenhardt, M. L. 1977. Vocal contour cues in maternal recognition of goat kids. Applied Animal Ethology, 3, 211-219. 
Lickliter, R. E. 1984. Hiding behavior in domestic goat kids. Applied Animal Behaviour Science, 12, 245251.

Lickliter, R. E. 1987. Activity patterns and companion preferences of domestic goat kids. Applied Animal Behaviour Science, 19, 137-145.

Lieblich, A. K., Symmes, D., Newman, J. D. \& Shapiro, M. 1980. Development of the isolation peep in laboratory-bred squirrel monkeys. Animal Behaviour, 28, 1-9.

McDougall, P. 1975. The feral goats of Kielderhead Moor. Journal of Zoology, 126, 215-246.

Mantel, N. 1967. The detection of disease clustering and a generalized regression approach. Cancer Research, 27, 209-220.

Mitani, J., Hunley, K. \& Murdoch, M. 1999. Geographic variation in the calls of wild chimpanzees: a reassessment. American Journal of Primatology, 47, 133-151.

Muller, J., Brunelli, S. \& Shair, H. 2009. Rat infant isolation vocalizations and their modulation by social cues as a model of expression of infantile emotionality. In: Handbook of Mammalian Vocalization: An Integrative Neuroscience Approach (Ed. by S. M. Brudzynski), pp. 227-240. Amsterdam: Elsevier.

Mundry, R. 1999. Testing related samples with missing values: a permutation approach. Animal Behaviour, 58, 1143-1153.

Noad, M. J., Cato, D. H., Bryden, M. M., Jenner, M.-N. \& Jenner, K. C. S. 2000. Cultural revolution in whale songs. Nature, 408, 537.

O'Brien, P. H. 1988. Feral goat social organization: a review and comparative analysis. Applied Animal Behaviour Science, 21, 209-221.

Poole, J. H., Tyack, P. L., Stoeger-Horwath, A. S. \& Watwood, S. 2005. Animal behaviour: elephants are capable of vocal learning. Nature, 434, 455-456.

R Development Core Team 2009. R Foundation for Statistical Computing. Vienna: R Foundation for Statistical Computing. http://www.R-project.org.

Reby, D. \& McComb, K. 2003. Anatomical constraints generate honesty: acoustic cues to age and weight in the roars of red deer stags. Animal Behaviour, 65, 519-530.

Saunders, F. C., McElligott, A. G., Safi, K. \& Hayden, T. J. 2005. Mating tactics of male feral goats (Capra hircus): risks and benefits. Acta Ethologica, 8, 103-110.

Schusterman, R. J. 2008. Vocal learning in mammals with special emphasis on pinnipeds. In: The Evolution of Communicative Flexibility: Complexity, Creativity, and Adaptability in Human and Animal Communication (Ed. by D. K. Oller \& U. Gribel), pp. 41-70. Cambridge, Massachusetts: MIT Press.

Seyfarth, R. M. \& Cheney, D. L. 2010. Production, usage, and comprehension in animal vocalizations. Brain and Language, 115, 92-100.

Simmons, A. M., Popper, A. N. \& Fay, R. R. 2003. Acoustic Communication. New York: Springer. 
Shi, J., Dunbar, R. I. M., Buckland, D. \& Miller, D. 2005. Dynamics of grouping patterns and social segregation in feral goats (Capra hircus) on the Isle of Rum, NW Scotland. Mammalia, 69, 185199.

Snowdon, C. T. 2009. Plasticity of communication in nonhuman primates. Advances in the Study of Behavior, 40, 239-276.

Sokal, R. R. \& Rohlf, F. J. 1995. Biometry: the Principles and Practice of Statistics in Biological Research. New York: W. H. Freeman.

Sueur, J., Aubin, T. \& Simonis, C. 2008. Equipment review: Seewave, a free modular tool for sound analysis and synthesis. Bioacoustics, 18, 213-226.

Sugiura, H. 1998. Matching of acoustic features during the vocal exchange of coo calls by Japanese macaques. Animal Behaviour, 55, 673-687.

Taylor, A. M. \& Reby, D. 2010. The contribution of source-filter theory to mammal vocal communication research. Journal of Zoology, 280, 221-236.

Titze, I. R. 1994. Principles of Voice Production. Englewood Cliffs, New Jersey: Prentice Hall.

Tyack, P. L. 2008. Convergence of calls as animals form social bonds, active compensation for noisy communication channels, and the evolution of vocal learning in mammals. Journal of Comparative Psychology, 122, 319-331. 


\section{Appendix}

Table A1: Results of the principal components analyses for 1-week-old kids

\begin{tabular}{|l|r|r|r|r|}
\hline Parameters & PC1 & PC2 & PC3 & PC4 \\
\hline Dur (s) & 0.35 & 0.07 & -0.22 & -0.33 \\
\hline F0Mean (Hz) & 0.15 & $\mathbf{0 . 9 4}$ & -0.15 & -0.15 \\
\hline F0Start $(\mathrm{Hz})$ & 0.15 & $\mathbf{0 . 9 0}$ & -0.13 & -0.12 \\
\hline F0End (Hz) & 0.02 & $\mathbf{0 . 9 1}$ & -0.05 & 0.03 \\
\hline F0Max (Hz) & 0.26 & $\mathbf{0 . 8 7}$ & -0.14 & -0.26 \\
\hline F0Min (Hz) & 0.02 & $\mathbf{0 . 9 6}$ & -0.09 & 0.06 \\
\hline F0AbsSlope (Hz/s) & 0.12 & -0.41 & 0.04 & -0.32 \\
\hline Q25\% (Hz) & $\mathbf{0 . 6 3}$ & -0.38 & -0.11 & -0.45 \\
\hline Q50\% $(\mathrm{Hz})$ & $\mathbf{0 . 6 5}$ & -0.26 & -0.01 & $-\mathbf{0 . 6 3}$ \\
\hline Q75\% $(\mathrm{Hz})$ & $\mathbf{0 . 5 5}$ & -0.03 & 0.10 & $-\mathbf{0 . 6 7}$ \\
\hline F1Min (Hz) & $\mathbf{0 . 5 5}$ & -0.20 & $-\mathbf{0 . 6 2}$ & 0.25 \\
\hline F2Min (Hz) & $\mathbf{0 . 8 1}$ & -0.15 & -0.31 & 0.25 \\
\hline F3Min (Hz) & $\mathbf{0 . 7 6}$ & -0.09 & 0.37 & 0.10 \\
\hline F4Min (Hz) & $\mathbf{0 . 5 4}$ & 0.08 & $\mathbf{0 . 7 3}$ & 0.13 \\
\hline F1Max (Hz) & $\mathbf{0 . 6 4}$ & 0.02 & $-\mathbf{0 . 5 5}$ & 0.13 \\
\hline F2Max (Hz) & $\mathbf{0 . 8 7}$ & 0.02 & -0.32 & 0.07 \\
\hline F3Max (Hz) & $\mathbf{0 . 8 3}$ & 0.11 & 0.33 & 0.11 \\
\hline F4Max (Hz) & $\mathbf{0 . 6 3}$ & 0.08 & $\mathbf{0 . 5 8}$ & 0.17 \\
\hline F1Mean (Hz) & $\mathbf{0 . 6 8}$ & -0.06 & $-\mathbf{0 . 6 2}$ & 0.22 \\
\hline F2Mean (Hz) & $\mathbf{0 . 8 7}$ & -0.05 & -0.33 & 0.17 \\
\hline F3Mean (Hz) & $\mathbf{0 . 8 5}$ & 0.01 & 0.39 & 0.10 \\
\hline F4Mean (Hz) & $\mathbf{0 . 6 3}$ & 0.09 & $\mathbf{0 . 7 0}$ & 0.17 \\
\hline DfMin (Hz) & 0.03 & 0.12 & $\mathbf{0 . 9 8}$ & -0.02 \\
\hline Eigenvalues & $\mathbf{2 . 7 9}$ & 2.17 & 2.06 & 1.31 \\
\hline Cum\%variance & $\mathbf{3 3 . 9}$ & 54.3 & 72.7 & 80.14 \\
\hline & & & & \\
\hline
\end{tabular}

The table shows factor loadings of the vocal parameters on the principal components (PC1e4) extracted from the PCA for 1-weekold kid calls. Bold type indicates the heaviest factor loadings $(r>0.50)$. Eigenvalues and cumulative explained variances (Cum\%variance) are also given. PC1 reflects the formant contour whereas PC2 reflects the F0 contour. 
Table A2: Results of the principal components analyses for 5-week-old kids

\begin{tabular}{|l|r|r|r|r|r|r|}
\hline Parameters & PC1 & PC2 & PC3 & \multicolumn{1}{|c|}{ PC4 } & \multicolumn{1}{c|}{ PC5 } & PC6 \\
\hline Dur (s) & 0.04 & -0.22 & 0.18 & -0.21 & $-\mathbf{0 . 7 0}$ & -0.09 \\
\hline F0Mean (Hz) & -0.28 & $\mathbf{0 . 8 6}$ & 0.34 & 0.00 & -0.03 & 0.02 \\
\hline F0Start (Hz) & -0.37 & $\mathbf{0 . 7 4}$ & 0.22 & 0.06 & -0.15 & 0.07 \\
\hline F0End (Hz) & -0.33 & $\mathbf{0 . 6 9}$ & 0.29 & 0.08 & 0.16 & 0.27 \\
\hline F0Max (Hz) & -0.24 & $\mathbf{0 . 8 5}$ & 0.29 & -0.04 & -0.04 & -0.02 \\
\hline F0Min (Hz) & -0.41 & $\mathbf{0 . 7 4}$ & 0.33 & 0.13 & 0.03 & 0.23 \\
\hline F0AbsSlope (Hz/s) & 0.20 & 0.16 & -0.11 & -0.09 & $\mathbf{0 . 5 8}$ & -0.30 \\
\hline Q25\% (Hz) & 0.28 & -0.19 & $\mathbf{0 . 7 4}$ & -0.27 & 0.20 & -0.28 \\
\hline Q50\% (Hz) & 0.36 & -0.30 & $\mathbf{0 . 7 4}$ & -0.36 & 0.13 & -0.14 \\
\hline Q75\% (Hz) & 0.39 & -0.31 & $\mathbf{0 . 7 0}$ & -0.33 & 0.10 & 0.00 \\
\hline F1Min (Hz) & 0.30 & 0.00 & 0.13 & $\mathbf{0 . 7 0}$ & 0.35 & -0.12 \\
\hline F2Min (Hz) & $\mathbf{0 . 6 8}$ & -0.18 & 0.03 & 0.28 & 0.23 & $\mathbf{0 . 4 4}$ \\
\hline F3Min (Hz) & $\mathbf{0 . 8 2}$ & 0.09 & 0.04 & -0.09 & 0.10 & 0.27 \\
\hline F4Min (Hz) & $\mathbf{0 . 7 4}$ & 0.44 & -0.22 & -0.07 & 0.13 & -0.17 \\
\hline F1Max (Hz) & $\mathbf{0 . 3 6}$ & 0.07 & 0.28 & $\mathbf{0 . 5 1}$ & -0.39 & $-\mathbf{0 . 4 2}$ \\
\hline F2Max (Hz) & $\mathbf{0 . 6 7}$ & -0.05 & 0.16 & 0.21 & -0.31 & 0.32 \\
\hline F3Max (Hz) & $\mathbf{0 . 7 1}$ & 0.24 & 0.01 & -0.18 & -0.27 & 0.13 \\
\hline F4Max (Hz) & $\mathbf{0 . 7 0}$ & 0.44 & -0.30 & -0.15 & -0.15 & -0.26 \\
\hline F1Mean (Hz) & $\mathbf{0 . 5 0}$ & 0.05 & 0.23 & $-\mathbf{0 . 6 7}$ & -0.08 & $-\mathbf{0 . 4 0}$ \\
\hline F2Mean (Hz) & $\mathbf{0 . 7 8}$ & -0.14 & 0.09 & 0.25 & 0.00 & $\mathbf{0 . 4 1}$ \\
\hline F3Mean (Hz) & $\mathbf{0 . 8 7}$ & 0.18 & 0.05 & -0.15 & -0.03 & 0.23 \\
\hline F4Mean (Hz) & $\mathbf{0 . 7 6}$ & 0.48 & -0.27 & -0.09 & 0.02 & -0.23 \\
\hline DfMin (Hz) & $\mathbf{0 . 6 1}$ & $\mathbf{0 . 5 3}$ & -0.34 & -0.39 & 0.02 & -0.13 \\
\hline Eigenvalues & 2.62 & 2.10 & 1.61 & 1.43 & 1.23 & 1.21 \\
\hline Cum\%variance & $\mathbf{2 9 . 9}$ & 48.9 & 60.2 & 69.03 & 75.59 & 81.92 \\
\hline
\end{tabular}

The table shows factor loadings of the vocal parameters on the principal components (PC1e6) extracted from the PCA for 5-weekold kid calls. Bold type indicates the heaviest factor loadings $(r>0.50)$. Eigenvalues and cumulative explained variances (Cum\%variance) are also given. PC1 reflects the formant con.tour whereas PC2 reflects the F0 contour. 
Table A3: Mean values of the vocal parameters for all the goat kids (overall) and for the four groups separately at 1 week old

\begin{tabular}{|c|c|c|c|c|c|c|c|c|c|c|}
\hline \multirow[t]{2}{*}{ Parameters } & \multicolumn{2}{|l|}{ Overall } & \multicolumn{2}{|l|}{ Group 1} & \multicolumn{2}{|l|}{ Group 2} & \multicolumn{2}{|l|}{ Group 3} & \multicolumn{2}{|l|}{ Group 4} \\
\hline & Mean & SE & Mean & SE & Mean & SE & Mean & SE & Mean & SE \\
\hline Dur (s) & & 0.01 & & 0.02 & & .02 & 39 & 0.03 & 0.27 & 0.03 \\
\hline FOMean $(\mathrm{Hz})$ & 587.56 & 6.85 & 624.03 & 8.60 & 636.46 & 14.28 & 569.71 & 12.50 & 19.88 & 12.67 \\
\hline F0Start (Hz) & 574.80 & 8.63 & 618.60 & 10.99 & 636.13 & 16.64 & 540.66 & 18.13 & 08.69 & 14.07 \\
\hline F0End & 568.44 & 7.07 & 619.89 & 8.12 & 620.71 & 14.16 & 544.11 & 12.18 & 88.48 & 12.37 \\
\hline FOMa> & 1.08 & 6.99 & & 05 & 7.34 & 5.10 & 98 & 13.27 & 1.03 & 4.22 \\
\hline F0Min $(\mathrm{Hz})$ & 538.07 & 7.60 & 594.42 & 10.11 & 605.54 & 14.46 & 491.51 & 13.38 & 468.18 & 10.94 \\
\hline F0AbsSlope & 571.96 & 27.49 & 309.29 & 31.19 & 40.86 & 62.77 & 727.98 & 47.70 & 9.81 & 55.02 \\
\hline Q25\% (Hz) & 1215.31 & 73.28 & 9.86 & 72.06 & 2.90 & 3.11 & 1885.91 & 165.27 & 1601.41 & 97.89 \\
\hline Q50\% (Hz) & 3002.22 & 122.77 & 1758.37 & 169.05 & 2370.06 & 184.22 & 4499.77 & 191.38 & 3030.45 & 198.38 \\
\hline Q75\% (Hz) & 6019.38 & 152.34 & 4644.95 & 279.50 & 669.78 & 320.07 & 7540.38 & 195.71 & 88 & 247.86 \\
\hline F1Min $(\mathrm{Hz})$ & 1397.75 & 34.64 & 1375.94 & 64.14 & 1123.42 & 1.66 & 1505.75 & 59.27 & 547.02 & 70.33 \\
\hline F2Min $(\mathrm{Hz})$ & 3658.93 & 73.06 & 3543.45 & 126.45 & 3192.95 & 111.63 & 4006.88 & 161.34 & 3776.34 & 132.49 \\
\hline F3Min $(\mathrm{Hz})$ & 6033.69 & 52.27 & 5866.94 & 105.07 & 5900.03 & 81.98 & 6411.78 & 98.93 & 5838.12 & 97.65 \\
\hline F4Min $(\mathrm{Hz})$ & 8126.22 & 51.64 & 8028.48 & 122.78 & 8219.30 & 77.26 & 8295.40 & 109.13 & 7913.56 & 59.78 \\
\hline F1Max $(\mathrm{Hz})$ & 2126.15 & 36.52 & 2085.01 & 69.86 & 2002.30 & 91.77 & 2335.16 & 57.98 & 2006.76 & 65.46 \\
\hline $\mathrm{F} 2 \mathrm{Max}(\mathrm{Hz})$ & 4528.80 & 70.12 & 4340.18 & 130.02 & 4292.42 & 133.64 & 4981.62 & 132.16 & 43 & 136.71 \\
\hline F3Max $(\mathrm{Hz})$ & 6835.32 & 52.96 & 6717.65 & 104.86 & 6826.06 & 92.49 & 7157.52 & 111.57 & 6534.69 & 71.01 \\
\hline $\mathrm{F} 4 \mathrm{Max}(\mathrm{Hz})$ & 9038.30 & 56.95 & 8937.08 & 141.00 & 8961.94 & 96.96 & 9346.93 & 106.43 & 8804.02 & 64.86 \\
\hline F1Mean $(\mathrm{Hz})$ & 1791.01 & 32.48 & 1789.38 & 60.87 & 1585.14 & 74.55 & 1937.88 & 55.12 & 1793.20 & 63.23 \\
\hline F2Mean $(\mathrm{Hz})$ & 4103.02 & 71.19 & 3962.30 & 128.31 & 3773.86 & 119.63 & 4478.13 & 149.53 & 4075.88 & 136.64 \\
\hline F3Mean $(\mathrm{Hz})$ & 6439.34 & 48.81 & 6276.67 & 94.70 & 6405.72 & 70.05 & 6777.91 & 101.79 & 6194.15 & 81.17 \\
\hline F4Mean $(\mathrm{Hz})$ & 8554.92 & 49.96 & 8469.68 & 125.04 & 8554.48 & 72.63 & 8797.72 & 99.40 & 8317.75 & 51.91 \\
\hline DfMin $(\mathrm{Hz})$ & 2265.52 & 21.12 & 2235.53 & 51.83 & 2353.99 & 37.82 & 2296.85 & 37.20 & 2169.20 & 32.85 \\
\hline
\end{tabular}

Sample size: group $1=48$ calls; group $2=40$ calls; group $3=56$ calls; group $4=40$ calls . 
Table A4: Mean values of the vocal parameters for all the goat kids (overall) and for the four groups separately at 5 weeks old

\begin{tabular}{|c|c|c|c|c|c|c|c|c|c|c|}
\hline \multirow[t]{2}{*}{ Parameters } & \multicolumn{2}{|l|}{ Overall } & \multicolumn{2}{|l|}{ Group 1} & \multicolumn{2}{|l|}{ Group 2} & \multicolumn{2}{|l|}{ Group 3} & \multicolumn{2}{|l|}{ Group 4} \\
\hline & Mean & SE & Mean & SE & Mean & SE & Mean & SE & Mean & SE \\
\hline Dur (s) & 0.64 & 0.02 & 0.61 & 0.02 & 0.55 & 0.05 & 0.73 & 0.04 & 0.66 & 0.05 \\
\hline FOMean $(\mathrm{Hz})$ & 545.08 & 3.78 & 543.69 & 6.42 & 590.47 & 8.61 & 521.40 & 5.37 & 534.50 & 6.42 \\
\hline F0Start (Hz) & 537.13 & 4.56 & 544.94 & 7.40 & 592.63 & 9.22 & 500.61 & 6.88 & 523.36 & 7.54 \\
\hline F0End $(\mathrm{Hz})$ & 507.75 & 4.26 & 504.67 & 7.52 & 560.05 & 8.94 & 479.84 & 6.12 & 498.22 & 7.47 \\
\hline FOMax $(\mathrm{Hz})$ & 572.80 & 3.79 & 574.40 & 6.97 & 613.47 & 9.14 & 551.76 & 5.25 & 559.67 & 6.18 \\
\hline F0Min (Hz) & 492.72 & 4.18 & 490.20 & 6.52 & 550.28 & 8.34 & 460.94 & 5.80 & 482.67 & 7.46 \\
\hline $\begin{array}{l}\text { F0AbsSlope } \\
(\mathrm{Hz} / \mathrm{s})\end{array}$ & 322.49 & 4 & 315. & 7 & 302 & 3 & 342 & 18.19 & 322.94 & 25.93 \\
\hline Q25\% (Hz) & 1302.36 & 46.78 & 781.67 & 80.75 & 1199.30 & 71.34 & 1578.33 & 79.25 & 1643.89 & 77.38 \\
\hline Q50\% (Hz) & 2823.24 & 85.67 & 1788.46 & 101.78 & 2640.36 & 166.80 & 3447.84 & 131.71 & 3373.44 & 160.59 \\
\hline Q75\% (Hz) & 5196.89 & 105.46 & 4097.60 & 176.43 & 4896.37 & 226.77 & 5933.37 & 158.40 & 5785.48 & 161.92 \\
\hline F1Min $(\mathrm{Hz})$ & 1348.82 & 19.54 & 1399.03 & 42.65 & 1217.64 & 32.93 & 1343.01 & 39.46 & 1427.86 & 27.71 \\
\hline F2Min $(\mathrm{Hz})$ & 3413.68 & 36.63 & 3497.77 & 48.19 & 2901.13 & 81.34 & 3509.56 & 64.25 & 3691.10 & 39.73 \\
\hline F3Min $(\mathrm{Hz})$ & 5278.37 & 33.68 & 5322.28 & 53.25 & 4930.60 & 82.06 & 5397.42 & 64.33 & 5406.76 & 37.23 \\
\hline F4Min (Hz) & 7068.47 & 43.18 & 7277.90 & 96.55 & 6720.21 & 87.01 & 7061.39 & 79.57 & 7175.34 & 44.05 \\
\hline F1Max (Hz) & 1972.71 & 19.82 & 1996.68 & 43.79 & 1856.88 & 30.06 & 2105.85 & 38.01 & 1873.37 & 26.36 \\
\hline F2Max $(\mathrm{Hz})$ & 4201.14 & 30.33 & 4217.94 & 57.73 & 3931.25 & 66.75 & 4373.34 & 55.65 & 4209.80 & 38.95 \\
\hline F3Max (Hz) & 6161.60 & 39.90 & 6219.72 & 80.02 & 5867.76 & 97.26 & 6406.55 & 66.69 & 6042.75 & 44.99 \\
\hline F4Max (Hz) & 8019.07 & 47.85 & 8345.14 & 116.64 & 7653.42 & 81.06 & 8079.91 & 84.21 & 7908.24 & 45.05 \\
\hline F1Mean (Hz) & 1691.41 & 15.01 & 1746.74 & 31.10 & 1537.43 & 23.82 & 1750.72 & 30.23 & 1695.96 & 16.28 \\
\hline F2Mean $(\mathrm{Hz})$ & 3814.10 & 28.63 & 3877.46 & 44.77 & 3438.45 & 65.93 & 3935.39 & 50.01 & 3943.93 & 28.38 \\
\hline F3Mean $(\mathrm{Hz})$ & 5692.70 & 32.26 & 5753.43 & 57.04 & 5352.77 & 74.64 & 5853.83 & 58.03 & 5734.19 & 38.49 \\
\hline F4Mean $(\mathrm{Hz})$ & 7514.67 & 41.01 & 7773.19 & 99.15 & 7162.53 & 73.51 & 7527.47 & 71.85 & 7538.64 & 35.21 \\
\hline DfMin $(\mathrm{Hz})$ & 1933.48 & 12.52 & 1990.48 & 32.47 & 1876.15 & 24.56 & 1926.66 & 21.64 & 1931.83 & 12.01 \\
\hline
\end{tabular}

Sample size: group $1=48$ calls; group $2=40$ calls; group $3=56$ calls; group $4=40$ calls. 
Figure A1. Goat kid call. Spectrogram (above) and oscillogram (below) of a call produced by a 5-week-old female kid. The black line at the bottom indicates the fundamental frequency (F0), and black dots above indicate the frequency values of the first four formants (F1e4). Segments are indicated above the spectrograms. Only formant values of the segments were kept for the analyses and intersegment values were omitted.

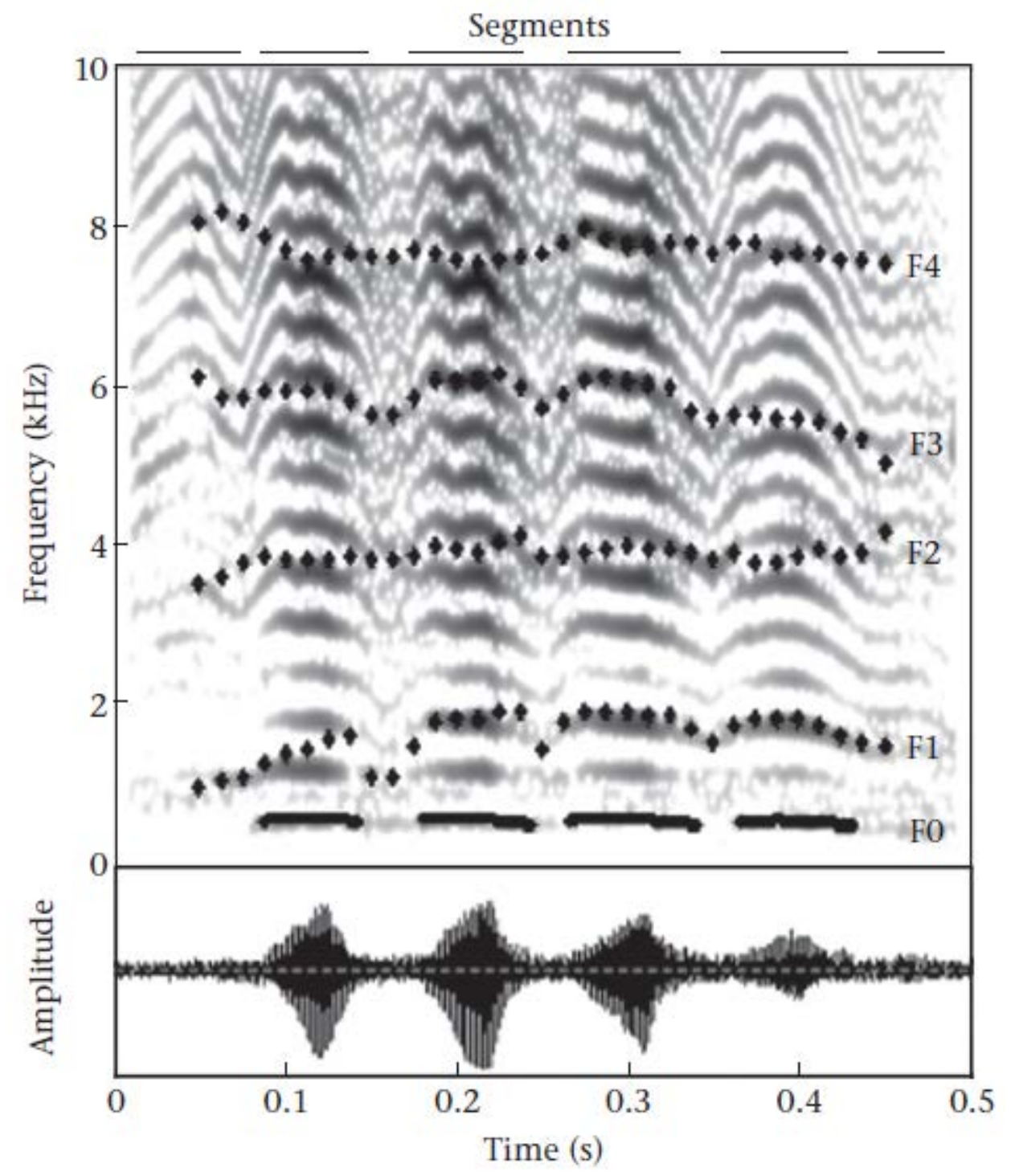

